\title{
A política de fundos e seus efeitos na municipalização do Ensino Fundamental
}

The funds policy and its effects on the municipalization of Fundamental Education

La politique de fonds et ses effets dans la municipalisation du Collège

Magna Jovita Gomes de Sales e Silva ${ }^{1}$ Secretaria Municipal de Educação de Teresina

Luis Carlos Sales ${ }^{2}$

Universidade Federal do Piauí

Resumo: Este artigo analisa os efeitos da política de fundos no processo de municipalização do ensino fundamental no estado do Piauí entre 1997 e 2019. Tomouse como ponto de partida o novo financiamento da educação pública no Brasil (Fundef/Fundeb). Conforme dados disponibilizados no site do Inep, ficou evidenciado que o processo de municipalização não ocorreu somente nos anos iniciais do ensino fundamental, mas veio a se configurar fortemente nos anos finais deste. As razões das peculiaridades da municipalização das matrículas do ensino fundamental no Piauí e os contextos econômicos e políticos, por não terem sido objeto deste artigo, ficarão como objeto de futuras pesquisas.

Palavras-chave: Matrículas. Ensino Fundamental. Municipalização.

Abstract: This article analyzes the effects of the fund policy on the process of municipalization of elementary education, in the state of Piauí, between 1997 and 2019. The new financing of public education in Brazil was taken as a starting point (Fundef / Fundeb). According to data made available on the INEP website, it became evident that the municipalization process did not occur only in the early years of elementary school, but came to take shape, strongly, in the final years of elementary school. The reasons for the peculiarities of the municipalization of enrollments in elementary education in Piauí and the economic and political contexts, as they were not the subject of this article, will remain the subject of future research.

Keywords: License plates. Elementary School. Municipalization.

Résumé : Cet article analyse les effets de la politique de fond dans le processus de municipalisation du collège, à l'état du Piauí, entre 1997 et 2019. Nous avons pris comme point de départ le nouveau financement de l'éducation publique au Brésil (Fundef/Fundeb). D'après des données disponibilisées sur le site du INEP, il a été évident que le processus de municipalisation n'a pas eu lieu seulement dans les années

\footnotetext{
${ }^{1}$ Doutora em Educação - Universidade Federal do Piauí (UFPI). Atua na Secretaria Municipal de Educação de Teresina (Semec). E-mail: magnajgss@hotmail.com. Lattes: http://lattes.cnpq.br/4455000642507657. ORCID: https://orcid.org/0000-0001-9730-8076.

2 Doutor em Educação, Universidade Federal do Piauí (UFPI) Professor da Universidade Federal do Piauí (UFPI). Email:1wis2006@gmail.com. Lattes: http://lattes.cnpq.br/3467660796249780. ORCID: https://orcid.org/0000-00019006-8401.
} 
Revista Educação e Políticas em Debate - v. 10, n. 1, p. 243-261, jan./abr. 2021 - ISSN 2238-8346 initiales du collège, mais il s'est configuré, fortement, dans ses années finales aussi. Les raisons des particularités de la municipalisation des inscriptions du collège au Piauí et les contextes economiques et politiques, qui n’ont pas été traités comme objet de cet article, resteront comme objet des prochaines recherches.

Mots-clés: Inscriptions. Collège. Municipalisation.

Recebido em: 18 de outubro de 2020 Aceito em: 19 de novembro de 2020

\section{Introdução}

Uma das lutas marcantes da sociedade civil organizada no Brasil consiste na defesa da garantia de oferta da educação escolar com atendimento universalizado, sobretudo com igualdade de condições da oferta e padrão de qualidade capaz de garantir o processo de ensino-aprendizagem. A materialização desse direito passa pela redistribuição de competências e responsabilidades das três instâncias governamentais, conforme expresso na Constituição Federal de 1988 (CF/88) e na atual Lei de Diretrizes e Bases da Educação Nacional (LDB/96), cabendo aos municípios a responsabilidade pela maior parte do atendimento da educação básica.

Na década de 1970, antes mesmo da promulgação da CF/88, a municipalização ou o aumento das responsabilidades dos municípios pelo atendimento educacional já estavam previstos na legislação com a instituição da Lei 5.692/71. No art. 58 da referida lei consta que, no desenvolvimento dos diferentes graus de ensino, a legislação estadual supletiva estabelece as responsabilidades dos estados e de seus municípios, devendo dispor de medidas que visem tornar mais eficiente a aplicação dos recursos públicos destinados à educação com vistas à progressiva passagem para a responsabilidade dos municípios de encargo e serviços de educação. Constata-se, assim, que a Lei $5.692 / 71$ já trazia orientações que se encaminhavam para a municipalização do ensino, preceito que mais tarde passou a constar na $\mathrm{CF} / 88$.

A divisão de responsabilidades entre as dependências administrativas está definida no art. $211 \mathrm{da} \mathrm{CF} / 88$, na legislação que regulamenta o sistema educacional no Brasil, reforçada pela LDB/96. Na divisão de responsabilidades, compete à União organizar o sistema federal de ensino e o dos territórios, financiar as instituições de ensino públicas federais e, em matéria educacional cumprir com a função redistributiva e supletiva com vistas a garantir a "equalização de oportunidades educacionais e o padrão mínimo de qualidade do ensino mediante assistência técnica e financeira aos 
Revista Educação e Políticas em Debate - v. 10, n. 1, p. 243-261, jan./abr. 2021 - ISSN 2238-8346 Estados, ao Distrito Federal e aos Municípios”, conforme alterações sofridas, ainda em 1996, com a aprovação da Emenda Constitucional nº 14 (BRASIL, 1988).

Ainda com base na Emenda Constitucional n ${ }^{\circ} 14\left(\mathrm{EC} \mathrm{n}^{\circ} 14\right)$, é de competência dos municípios atuar no ensino fundamental e na educação infantil de forma prioritária, cabendo aos estados e ao Distrito Federal priorizar o atendimento do ensino fundamental e médio. Ademais, alterações no parágrafo $4^{\circ}$ do art. 21 , pela $\mathrm{EC} \mathrm{n}^{\circ}$ 59/2009, determinam que União, o Distrito Federal, estados e municípios estabeleçam formas de colaboração tendo como objetivo a universalização do ensino obrigatório (de 4 a 17 anos). Com a aprovação da $\mathrm{EC} \mathrm{n}^{\circ}$ 108, o parágrafo $4^{\circ}$ sofreu nova redação, passando a incluir, como produto dessa colaboração, a garantia da qualidade e da equidade na oferta educacional no País.

A reordenação das responsabilidades municipal, estadual e federal não é algo recente, foi incluída na nossa história ainda na década de 1940, ganhando avanços com o pensamento de Anísio Teixeira ainda em 1957, que considerava que esse modelo contribuiria para o fortalecimento e a consolidação das instituições escolares. Visão um pouco simplista e romântica para a atualidade, "porque ignorava, deliberadamente, toda a complexidade do jogo político que cerca o traçado de uma política educacional de dimensões tão amplas” (AZANHA 1991, p. 62).

A $\mathrm{CF} / 88$ pôs um direcionamento claro para a municipalização das políticas públicas e sociais, garantindo "recursos e regimes de colaboração entre as esferas de governo para a consecução das novas incumbências”. No decorrer dos anos 1990, a descentralização sai do plano discursivo com a aprovação do Fundo de Manutenção e Desenvolvimento do Ensino Fundamental e de Valorização do Magistério (Fundef), que, na concepção do referido autor, constituiu-se como a ação mais importante para fazer avançar o processo de municipalização da educação (CASTRO 2007, p. 7).

Neste artigo, analisam-se os efeitos da política de fundos no processo de municipalização do ensino fundamental no estado do Piaú entre 1997 e 2019 na perspectiva de ampliar estudo que discute essa temática, o qual foi publicado em 2013 por Sales e Silva, que analisou o período de 1997 a 2010. A construção desse objetivo guiou-se a partir de duas questões, a saber: qual o comportamento das matrículas na educação básica, de modo específico, no ensino fundamental nas redes de ensino estadual e municipal no Piauí? O processo de municipalização das matrículas no ensino fundamental, intensificado no Piauí durante o período do Fundef, permaneceu ao longo da vigência do Fundo de Manutenção e Desenvolvimento da Educação Básica e de Valorização dos Profissionais da Educação Fundeb? A partir desses questionamentos, fez-se o levantamento das matrículas do censo 
Revista Educação e Políticas em Debate - v. 10, n. 1, p. 243-261, jan./abr. 2021 - ISSN 2238-8346 escolar disponível na página do Inep. Os dados de matrículas foram sistematizados em tabelas que se encontram distribuídas ao longo deste texto.

Para uma melhor compreensão e análise do objeto deste artigo, considerou-se importante incluir, na série histórica, dados de matrícula do primeiro ano de vigência do Fundef (1997) que podem expressar as configurações e os reflexos de uma das políticas de financiamento da educação voltada para a educação básica que, pela sua singularidade, intensificou os debates nos diversos setores da sociedade.

A temática envolvida neste artigo constitui objeto de interesse de muitos pesquisadores no momento em que se constata a existência de um número significativo de trabalhos publicados em revistas, comunicações orais etc. No que pese a publicação de artigos em revistas, o tema foi abordado recentemente por vários pesquisadores, especialmente por conta das discussões em torno do processo de votação do novo Fundeb, que culminou com a aprovação da EC 108/2020, que se encontra aguardando sua regulamentação (CRUZ e SONOBE, 2020; DAVIES, 2020 NALU, 2020; PINTO e ALVES, 2020). Ademais, anterior a esse processo, localizaram-se ainda os artigos de Souza e Farias em 2004. Nesse trabalho, discute-se o contexto do processo de reforma do Estado brasileiro e suas relações com a descentralização da educação via municipalização, e os desafios postos à educação municipal no País.

Em estudo publicado recentemente por Pinto e Alves (2020), fica evidente que a oferta da educação básica pública no Brasil apresentou queda sistemática nas matrículas em todas as etapas e modalidades, em especial a partir de 2000 na rede estadual. Por outro lado, os percentuais de participação da rede municipal cresceram sucessivamente, saindo de 44\%, em 1998, para 55\%, em 2007, atingindo 59\%, em 2017. Os autores concluem que houve um avanço significativo na municipalização do ensino fundamental em todos os aportes populacionais analisados, especialmente nos municípios entre 10 mil e 50 mil habitantes, os quais atingiram um grau de municipalização superior a $75 \%$, e que o Nordeste é uma região com peso significativo nesse aporte populacional.

Ainda sobre a municipalização das matrículas do ensino fundamental durante a vigência do Fundeb, Cruz e Sonobe (2020) afirmam a sua continuidade nos anos iniciais nas regiões Norte e Nordeste. Especificamente sobre os anos finais, as autoras constataram maior municipalização no Ceará, no Maranhão, na Bahia e no Piauí, com 96,6\%, 95,2\%, 82,3\% e 81,1\%, respectivamente. Por outro lado, o Paraná, com 1,5\%, Roraima, com 2,2\% e o Amapá, com 4\%, são os estados com as menores taxas de municipalização (CRUZ e SONOBE, 2020, p. 13). 
Revista Educação e Políticas em Debate - v. 10, n. 1, p. 243-261, jan./abr. 2021 - ISSN 2238-8346

Outros estudos concluem que a municipalização é um fenômeno que já atingiu índices elevados em alguns estados. Isto se deve às mudanças no perfil da distribuição de responsabilidades entre estados e municípios no atendimento do ensino fundamental a partir de 1996, destacando-se como fator principal a implantação da política de fundos, fato que passou a ser considerado como uma política indutora da municipalização e da ampliação do atendimento do ensino fundamental no Brasil (GUIMARÃES; PINTO, 200 1; ARELARO, 2007; CALLEGARI, 2011 ; MILITÃO, 2011).

Santos (2003) apresenta os rumos da municipalização do ensino nas séries iniciais do ensino fundamental nos municípios paranaenses e conclui que esse processo ocorreu mesmo antes da criação do Fundef, embora sua intensificação tenha sido uma das suas principais finalidades. No texto "Federalismo, descentralização e planejamento da educação: desafios aos municípios”, Pinto (2014) problematiza sobre os desafios que se apresentam para os gestores municipais diante da expansão do atendimento educacional a partir da implementação da política de fundos.

Considerando os aspectos trabalhados nas diferentes pesquisas realizadas no Brasil, constatou-se que no Piauí apenas um trabalho foi publicado, o qual tem como foco o processo de municipalização das matrículas da educação básica. Os resultados dessa pesquisa revelam que o processo de municipalização no referido estado assumiu configurações peculiares por apresentar-se fortemente nos anos finais do ensino fundamental e não somente em seus anos iniciais (SALES e SILVA, 2013).

É nesse contexto que se justifica a realização deste artigo, por considerar que ainda existem lacunas no campo das discussões sobre o tema, especialmente levando-se em conta que no trabalho de Sales e Silva (2013) não foi possível analisar o processo da municipalização das matrículas da educação básica considerando os últimos nove anos de vigência do Fundeb, recorte temporal agora considerado para a produção deste artigo.

Para uma melhor compreensão do artigo, o trabalho apresenta esta introdução, em seguida, faz uma discussão teórica sobre a política de fundos para o financiamento da educação básica implantada no Brasil a partir do Fundef, e, na sequência, apresenta os achados da pesquisa e as conclusões possíveis a partir da análise dos dados.

\section{O financiamento da Educação Básica a partir de 1997}

A CF/88 confiou aos municípios atuação prioritária na educação infantil e no ensino fundamental; aos estados e ao Distrito Federal, delegou a atuação prioritária no ensino fundamental e no ensino médio. Apesar das determinações constitucionais reafirmadas na 
Revista Educação e Políticas em Debate - v. 10, n. 1, p. 243-261, jan./abr. 2021 - ISSN 2238-8346 LDB/96, não foi possível impedir que os entes federados realizassem atendimento fora das áreas prioritárias. Depois da LDB/96, houve uma movimentação natural de matrículas da educação infantil dos estados para os municípios, e as matrículas dos municípios que atendiam ao ensino médio foram transferidas para as redes estaduais. O ensino fundamental, embora prioridade dos municípios, passou a ser assegurado pelos estados, portanto essa etapa do ensino poderia ser oferecida tanto pelas redes municipais quanto pelas redes estaduais. Sendo assim, no caso da educação infantil e do ensino médio, não houve necessidade de as redes estaduais e municipais disputarem esses atendimentos.

No tocante ao financiamento da educação, a CF/88 determina que estados, municípios e o Distrito Federal devem aplicar, no mínimo, 25\% da receita resultante de impostos, compreendida a proveniente de transferências, na manutenção e no desenvolvimento do ensino. De 1998 até 2007, com a instituição do Fundef, o foco do financiamento foi o ensino fundamental, pois dos $25 \%$ destinados à educação, $15 \%$, obrigatoriamente, deveriam ser aplicados exclusivamente no ensino fundamental. Os 10\% restantes deveriam ser destinados às demais etapas e modalidades da educação básica e ao ensino superior. A opção pelo ensino fundamental provocou o crescimento das matrículas, as quais atingiram, em poucos anos, a quase universalização (98\%). O fato de o Fundef financiar apenas o ensino fundamental trouxe impacto negativo no atendimento da educação infantil, no ensino médio e na Educação de Jovens e Adultos (EJA). Isso porque os gestores das redes estaduais, para não perderem recursos, terminaram negligenciando o atendimento do ensino médio (sua área prioritária) e voltaram suas atenções para o ensino fundamental, passando a concorrer com as redes municipais nas matrículas para essa etapa de ensino.

No caso da educação infantil e do ensino médio, não houve mudanças significativas no que se refere à oferta de matrículas pelas redes estaduais e municipais. As disputas pelo atendimento passaram a acontecer em alguns estados em relação aos alunos do ensino fundamental, havendo uma tendência de os municípios se destacarem no atendimento dos anos iniciais e os estados no atendimento dos anos finais. Isso em função do novo mecanismo de redistribuição dos recursos, que utilizava o quantitativo de matrículas apurado no Censo Escolar do ano anterior, em que cada aluno contabilizado era revertido em receita no ano seguinte. Nessa lógica, ficava desenhado o novo cenário do financiamento da educação pública no Brasil de um ano para o outro. Esse processo configurou-se como sendo o início do fenômeno das transferências de matrícula das redes estaduais para as municipais a partir de 1998, e que ficou conhecido como municipalização do ensino.

Para se compreender melhor como se deu a dinâmica da movimentação das matrículas das redes estadual e municipal no estado do Piauí, é preciso, antes, que seja 
Revista Educação e Políticas em Debate - v. 10, n. 1, p. 243-261, jan./abr. 2021 - ISSN 2238-8346 apresentada a lógica de financiamento instituída pelo Fundef/Fundeb, apresentando-se, em seguida, discussão sobre o fenômeno da municipalização no Brasil.

\section{O financiamento da educação básica: do FUNDEF ao FUNDEB}

A política de fundos alterou a divisão de responsabilidades pela oferta da educação básica entre estados e municípios ao redistribuir recursos no âmbito de cada estado da federação, considerando as matrículas da educação básica, inicialmente priorizando apenas o ensino fundamental, no caso do Fundef, e depois, com o Fundeb, havendo a ampliação para toda a educação básica. Vários estudos apontam que os municípios brasileiros vêm assumindo uma enorme responsabilidade no tocante ao atendimento educacional, particularmente a partir da aprovação do Fundef. Pesam sobre os municípios, portanto, a responsabilidade pelas etapas de ensino que exigem maior investimento financeiro, além de, muitos deles, serem desprovidos de condição técnica para implementar um planejamento e executar políticas educacionais, além de não terem autonomia financeira nem condições de adquiri-la, a menos que o Brasil adote uma reforma tributária radical (NALÚ, 2020; ARELARO, 2007; PINTO, 2014; PINTOS e ALVES, 2020). Para melhor compreender todas essas questões, é importante relembrar, de forma breve, como funcionava o Fundef.

O referido fundo mudou a lógica do financiamento do ensino fundamental. A partir de então, foi criado, no âmbito de cada estado, um fundo de natureza contábil que arrecadava $15 \%$ de alguns impostos e transferências (FPM e FPE). A arrecadação do Fundef era rateada entre as redes de ensino (estadual e municipal) de forma proporcional à quantidade de alunos matriculados no ano anterior. Portanto, quanto maior a quantidade de matrículas, maior seria o volume de recursos repassados a uma rede de ensino. Em função dessa lógica, estabeleceu-se, no Piauí, uma disputa pelos alunos do ensino fundamental.

Neste sentido, cada rede de ensino procurava ampliar seu atendimento. Conforme foi dito anteriormente, as redes de ensino, a fim de receber um repasse maior de recursos do Fundef, recorriam a campanhas publicitárias com vistas a atrair mais alunos. Várias estratégias eram utilizadas pelas redes estaduais e municipais para ampliar suas matrículas, uma vez que, no contexto de um mesmo município, geralmente havia escolas municipais e estaduais realizando o mesmo atendimento. Assim, dependendo do contexto de cada estado, as matrículas do ensino fundamental passaram a ser objeto de disputa entre estado e município.

Ainda sobre as receitas do Fundef, o Tesouro Nacional realizava cálculos para determinar o valor per capita no âmbito de cada estado. Para tanto, dividia o total arrecadado 
Revista Educação e Políticas em Debate - v. 10, n. 1, p. 243-261, jan./abr. 2021 - ISSN 2238-8346 no estado pelo total de alunos matriculados no ensino fundamental no ano anterior. Nos estados em que o valor per capita fosse menor que o valor-aluno fixado anualmente pela União, esta deveria repassar recursos (complementação) para o fundo daquele estado até igualar o valor per capita ao valor-aluno/ano fixado pela União.

Em 2007 foi instituído o Fundeb, e desde então toda a educação básica passou a ser contemplada com recursos do fundo. O valor aluno/ano passou a contemplar mais etapas e modalidades do referido nível de ensino, criando, assim, fatores de ponderação entre as etapas e modalidades. Assim como o Fundef, o Fundeb é um fundo de natureza contábil, formado a partir de parcela significativa das receitas vinculadas à educação definidas no art. $212 \mathrm{da} \mathrm{CF} / 88$, e por uma quantia destinada pela União a título de complementação, sempre que o valor por aluno não alcançasse o mínimo definido nacionalmente no âmbito de cada estado e do Distrito Federal.

O Fundeb apresenta aspectos que se assemelham ao Fundef, diferenciando-se por agregar maior volume de recursos, consequência da incorporação de novos impostos na sua composição, do acréscimo nos percentuais, de forma gradual, de 15\% para 20\% das receitas vinculadas destinadas à educação estabelecido pelo art. 212 da CF/88. Também com o Fundeb houve maior aporte de recursos da União, via complementação, para atender aqueles estados que não atingissem o mínimo anual por aluno estabelecido nacionalmente.

O que mudou na passagem do Fundef para o Fundeb a partir de 2007? Segundo Bassi e Fermino (2011, p. 11),

o FUNDEB preservou os mecanismos de captura e de redistribuição de recursos instaurados pelo FUNDEF. Estendeu, porém, significativamente a abrangência de financiamento a todas as etapas e modalidades da educação básica, contando, para isso, com um maior aporte de recursos decorrente da elevação do percentual subvinculado de um número maior de impostos (BRASIL, 2007). Implantado também em âmbito estadual, os novos fundos processam operações contábeis que recolhem a maior parte da receita gerada pela vinculação que os Estados, o DF e os Municípios têm de destinar às despesas com MDE e, depois, as redistribui aos governos, proporcionalmente de acordo com o número de matrículas de Educação Básica, obedecendo às competências estabelecidas no artigo 211 da $\mathrm{CF} / 88$.

Tanto no Fundef quanto no Fundeb, o governo federal passou a fixar anualmente um valor mínimo nacional por aluno (valor aluno/ano) com vistas a atender aos estados em que seus valores per capita não atingissem o referido valor mínimo nacional, atendimento esse que ficou conhecido como complementação da União. Esses dois fundos, portanto, impactaram significativamente na municipalização das matrículas. 
Revista Educação e Políticas em Debate - v. 10, n. 1, p. 243-261, jan./abr. 2021 - ISSN 2238-8346

\section{Municipalização: entre consensos e desacordos}

Os estudos relacionados à municipalização, em geral, destacam pontos positivos no processo de implementação, por possibilitar, via descentralização, melhor atendimento educacional, tendo em vista que os municípios são as instâncias mais próximas daqueles que demandam os serviços públicos. O princípio da descentralização foi uma ideia defendida no Manifesto dos Pioneiros da Educação Nova, em 1932. O programa de reforma proposto no manifesto argumentava que o Estado deveria adotar uma política global e nacional, abrangendo todos os níveis e modalidades de educação e ensino, enquanto, na organização dos serviços e dos sistemas de educação e ensino, seria “[...] adotado o princípio da descentralização administrativa […]” (LEMME, 2005, p. 172).

O contraponto dessa discussão aparece através das críticas elaboradas à municipalização das matrículas. Nesse contexto, a municipalização se apresenta como um processo de desresponsabilização de uma instância central para uma periférica. Uma crítica encontrada em alguns estudos diz respeito à imposição constitucional para que os municípios assumam maiores responsabilidades com a garantia de políticas sociais, como a oferta do ensino fundamental obrigatório, sem combinar com uma reorganização tributária. Ou seja, o governo federal transfere parcela significativa de responsabilidades à esfera municipal, enquanto se mantém no controle da maior parcela de recursos financeiros.

Para Arelaro (2007), cerca de 70\% dos municípios brasileiros não possuem autonomia financeira para suas despesas regulares e, portanto, apresentam pouca condição de se viabilizarem como entes autônomos, principalmente porque dependem exclusivamente de recursos originados do FPM (Fundo de Participação dos Municípios). Com esse modelo de municipalização, ampliam-se as desigualdades entre os municípios ricos e os mais pobres. Esses últimos, sem autonomia financeira, não encontram condições de cumprirem com suas novas responsabilidades, transformando-se, no máximo, em meros “[ $\ldots$.$] executores de$ programas nacionais e estaduais [...]” (ARELARO, 2007, p. 04).

Ademais, a discussão sobre municipalização do ensino no Brasil não é nova e há muito tempo vem ocupando a atenção de educadores, políticos, administradores e especialistas em Educação. As propostas discutidas tinham inspiração no modelo educacional norte-americano, o qual era fortemente descentralizado (MILITÃO, 2011). Na década de 1970, a municipalização passou a ser amparada na legislação, com a instituição da Lei 5.692/71, a qual orientava os municípios a assumirem as primeiras etapas da educação básica, apontando para a municipalização do ensino. 
Revista Educação e Políticas em Debate - v. 10, n. 1, p. 243-261, jan./abr. 2021 - ISSN 2238-8346

Como se observa na Lei 5.692/71, o ensino fundamental (então ensino de $1^{\circ}$ grau) passava a ser de responsabilidade dos municípios, e, com a $\mathrm{CF} / 88$, essa responsabilidade se estendeu à educação infantil (ensino pré-escolar). Segundo Souza e Faria (2004, p. 926), o contexto da constituinte de 1988

[...] foi marcado por fortes reações ao centralismo do regime autoritário e por uma grande revalorização da instância local, e apesar da pluralidade de interesses, definiu-se a tendência de atribuição de uma maior autonomia aos Municípios, confirmada, no campo da educação, alguns anos após, pela nova Lei de Diretrizes e Bases da Educação (LDB) - Lei nº 9.394 -, em 1996.

De acordo com Guimarães e Pinto (2001), a municipalização avançou tanto na região Nordeste, onde os municípios já tinham assumido mais da metade da rede pública de ensino fundamental, quanto no Sudeste, onde es sa participação, em 1996, era de apenas um quarto do total. Os referidos autores chamam atenção para o fato de ser exatamente nas regiões mais pobres do País onde mais avançou a responsabilização dos municípios pelo ensino fundamental.

Para Bassi e Fermino (2011), a instituição do Fundef criou mecanismo de indução que estimulou os municípios a ampliarem seu atendimento no ensino fundamental com vistas a obter mais receitas ou, pelos menos, para recuperar a parcela automaticamente retida pelo Fundef. $\mathrm{O}$ efeito do Fundef, nos seus primeiros anos de vigência, teve impacto, em nível nacional, na municipalização do ensino fundamental, movimento observado com a transferência de matrículas da esfera estadual para a municipal e com a expressiva expansão da oferta.

Ainda segundo Bassi e Fermino (2011, p. 05-06), o Fundef promoveu

imediata e substancial transferência de recursos financeiros dos governos estaduais aos municipais, na maioria dos estados da Região Nordeste, onde o ensino fundamental se encontrava municipalizado desde a década de 1970. O oposto ocorreu em estados das Regiões Sul e Sudeste, onde a matrícula se concentrava na rede estadual.

As afirmações de Bassi e Fermino (2011) reforçam os achados de Guimarães e Pinto (2001), os quais apresentaram resultados sobre a municipalização do ensino fundamental que ocorreu em todas as regiões do Brasil. As afirmações desses dois autores reafirmam a necessidade de se analisar a movimentação das matrículas do ensino fundamental no estado do Piauí com o objetivo de preencher uma lacuna e de conhecer a especificidade do fenômeno da municipalização no estado.

Dentro dos limites deste trabalho, por falta de espaço, não se entrará no mérito das vantagens e desvantagens da municipalização. Sendo assim, para efeitos de análise, aqui, a 
Revista Educação e Políticas em Debate - v. 10, n. 1, p. 243-261, jan./abr. 2021 - ISSN 2238-8346 municipalização toma como foco o processo de transferência de matrículas da rede estadual para a municipal no âmbito do estado do Piauí como estratégia para acelerar o processo de descentralização do ensino a partir da implantação do Fundef.

\section{As matrículas no Piauí a partir do FUNDEF/FUNDEB}

Para analisar a oferta de matrículas na educação básica no estado do Piauí, foi elaborada uma série histórica com dados de matrículas compreendendo informações de 1997, ainda na vigência do Fundef, e continuando de 2011 a 2019, já no Fundeb, tendo como fonte o site do Inep.

TABELA 1 - Matrículas da Educação Básica no Piauí das redes estadual e municipal (1997 - 2019)

\begin{tabular}{l|c|c|c|c|c}
\hline $\mathbf{A N O}$ & ESTADUAL & MUNICIPAL & $\begin{array}{c}\text { MATRÍCULA } \\
\text { TOTAL }\end{array}$ & ESTADUAL ( \% ) & MUNICIPAL ( \% ) \\
\hline $\mathbf{1 9 9 7}$ & 307.947 & 415.606 & 723.553 & 42,6 & 57,4 \\
\hline $\mathbf{2 0 1 1}$ & 293.539 & 560.914 & 854.453 & 34,4 & 65,6 \\
\hline $\mathbf{2 0 1 2}$ & 277.796 & 553.761 & 831.557 & 33,4 & 66,6 \\
\hline $\mathbf{2 0 1 3}$ & 238.145 & 570.092 & 808.237 & 29,5 & 70,5 \\
\hline $\mathbf{2 0 1 4}$ & 231.772 & 561.330 & 793.102 & 29,2 & 70,8 \\
\hline $\mathbf{2 0 1 5}$ & 221.995 & 544.614 & 766.609 & 29,0 & 61,0 \\
\hline $\mathbf{2 0 1 6}$ & 273.939 & 536.707 & 810.646 & 33,8 & 64,2 \\
\hline $\mathbf{2 0 1 7}$ & 305.444 & 546.650 & 852.094 & 35,8 & 64,2 \\
\hline $\mathbf{2 0 1 8}$ & 302.252 & 541.078 & 843.330 & 35,8 & 69,4 \\
\hline $\mathbf{2 0 1 9}$ & 236.000 & 534.736 & 770.736 & 30,6 & \\
\hline
\end{tabular}

Fonte: Elaborado pelos autores a partir de dados do Inep.

GRÁFICO 1 - Matrículas da Educação Básica no Piauí das redes estadual e municipal (1997 - 2019)

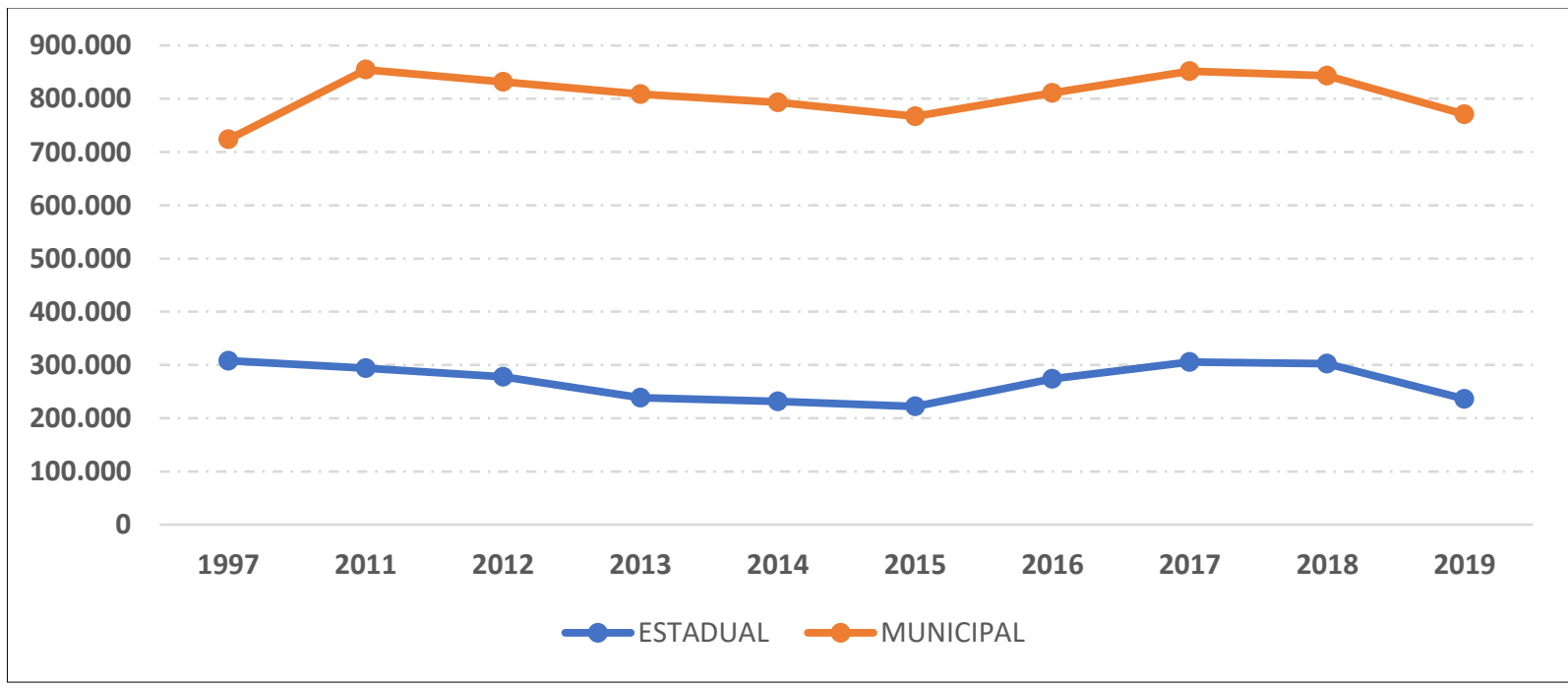

Fonte: Elaborado pelos autores a partir de dados do Inep.

Conforme a Tabela 1 e o Gráfico 1, constata-se que as matrículas da educação básica das redes municipais, de 1997 a 2011, apresentaram um crescimento expressivo, saindo de 
Revista Educação e Políticas em Debate - v. 10, n. 1, p. 243-261, jan./abr. 2021 - ISSN 2238-8346 415.606 para 560.914 matrículas, representando um crescimento de 145.308 novos alunos. No entanto, de 2011 a 2019, há uma redução de 26.178 matrículas na educação básica. Em relação à rede estadual, de 1997 a 2015, observa-se uma queda constante de matrículas (totalizando 85.952) na educação básica. Nos dois anos seguintes (2016 e 2017) há reversão, constatando-se crescimento e o maior patamar das matrículas estaduais (305.444). Esse aumento de matrículas da rede estadual na educação básica foi motivado pelo expressivo crescimento de matrículas em EJA (Educação de Jovens e Adultos), ampliando em mais de 100.000 novos alunos, o que pode ser explicado por intensa campanha realizada pela Secretaria de Estado da Educação do Piauí. Essa tendência de crescimento só foi suspensa em função dos prejuízos provocados pela trava do Fundeb, que limita em 15\% o percentual máximo de matrículas em EJA em relação às matrículas totais.

Esse aumento significativo das matrículas em EJA mudou a tendência de aumento do percentual de municipalização da educação básica no Piauí, que atingiu seu percentual máximo em 2015 (71,0\%), diminuindo em 2016 (66,2\%), 2017 (64,2\%) e 2018 (64,2\%), voltando a aumentar em 2019 (69,4 \%) em função da redução das matrículas em EJA em razão dos prejuízos provocados pela trava do Fundeb, o que levou a Secretaria de Estado da Educação do Piauí a repensar sua política de expansão do atendimento na referida modalidade.

A perda de matrículas observada a partir de 2011 deve-se em parte ao efeito demográfico expresso pela diminuição da quantidade de nascidos vivos no Piauí. Nessa linha de raciocínio, Amaral (2010) corrobora essa justificativa de redução de matrículas no país. Segundo o autor, no Brasil, em 2008, o percentual da população em idade educacional representava 44\%. Esse percentual deverá cair, em 2050, para 24\%. Portanto, para o autor, o perfil da população está mudando, pois, com o passar dos anos, a população jovem diminuirá em relação à população mais velha.

Conforme Bassi e Fermino (2011), no Brasil, outro fator que contribuiu para a redução das matrículas está relacionado com a mudança na metodologia utilizada pelo Inep a partir de 2007 para realizar o Censo Escolar, o Educacenso, que, ao informatizar a coleta de informações educacionais, eliminou as matrículas duplicadas.

Em seguida, são analisadas as matrículas do ensino fundamental do Piauí, observando-se inicialmente a movimentação das matrículas nos anos iniciais do ensino fundamental nas duas redes consideradas. 
Revista Educação e Políticas em Debate - v. 10, n. 1, p. 243-261, jan./abr. 2021 - ISSN 2238-8346

TABELA 2 - Matrículas dos anos iniciais do ensino fundamental no Piauí das redes estadual e municipal (1997-2019)

\begin{tabular}{c|c|c|c|c|c}
\hline ANO & ESTADUAL & MUNICIPAL & $\begin{array}{c}\text { MATRÍCULA } \\
\text { TOTAL }\end{array}$ & ESTADUAL ( \% ) & MUNICIPAL ( \% ) \\
\hline $\mathbf{1 9 9 7}$ & $\mathbf{1 6 0 . 7 0 3}$ & $\mathbf{3 2 8 . 8 7 5}$ & $\mathbf{4 8 9 . 5 7 8}$ & $\mathbf{3 2 , 8}$ & $\mathbf{6 7 , 2}$ \\
\hline $\mathbf{2 0 1 1}$ & 37.344 & 252.147 & 289.491 & 12,9 & 87,1 \\
\hline $\mathbf{2 0 1 2}$ & 28.046 & 244.331 & 272.377 & 10,3 & 89,7 \\
\hline $\mathbf{2 0 1 3}$ & 8.886 & 250.598 & 259.484 & 2,4 & 96,6 \\
\hline $\mathbf{2 0 1 4}$ & 6.048 & 246.063 & 252.111 & 1,7 & 97,6 \\
\hline $\mathbf{2 0 1 5}$ & 4.195 & 243.737 & 247.932 & 1,4 & 98,3 \\
\hline $\mathbf{2 0 1 6}$ & 3.282 & 238.591 & 241.873 & 1,2 & 98,6 \\
\hline $\mathbf{2 0 1 7}$ & 2.747 & 235.536 & 238.283 & 1,0 & 99,0 \\
\hline $\mathbf{2 0 1 8}$ & 2.235 & 228.845 & 231.080 & 0,9 & 99,1 \\
\hline $\mathbf{2 0 1 9}$ & 1.966 & 221.478 & 223.444 & & \\
\hline
\end{tabular}

Fonte: Elaborado pelos autores a partir de dados do Inep.

GRÁFICO 2 - Matrículas dos anos iniciais do ensino fundamental no Piauí das redes estadual e municipal (1997-2019)

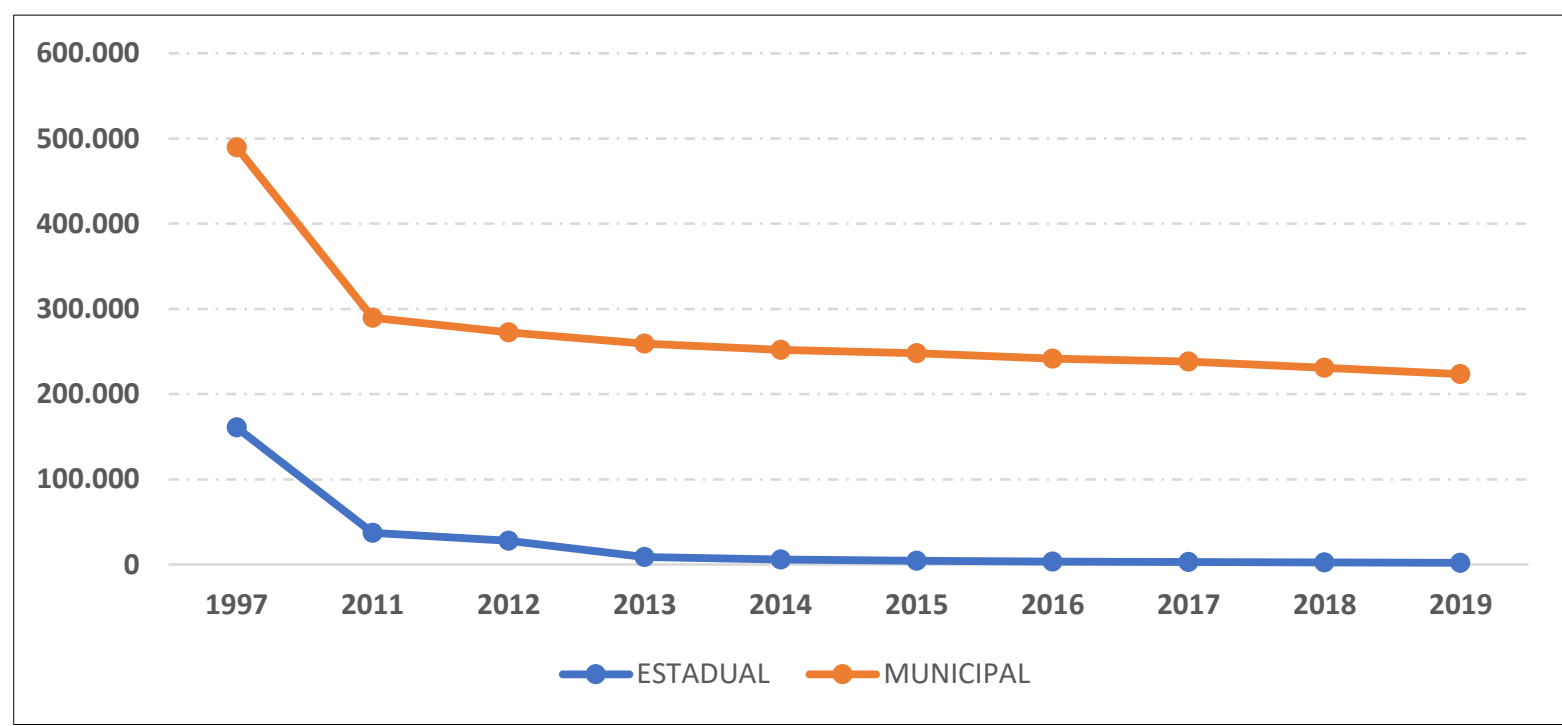

Fonte: Elaborado pelos autores a partir de dados do Inep e do Observatório da Educação

Na Tabela 2 e no Gráfico 2, pode ser observada a movimentação das matrículas dos anos iniciais do ensino fundamental no Piauí referentes às redes estadual e municipal. Percebe-se que houve uma redução geral das matrículas nas duas redes (estadual e municipal). Em relação à rede estadual, em 1997, existiam 160.703 alunos, quantidade que cai expressivamente para 1.966, havendo uma redução de 158.737 matrículas. Considerando o total de matrículas das duas dependências administrativas, 
Revista Educação e Políticas em Debate - v. 10, n. 1, p. 243-261, jan./abr. 2021 - ISSN 2238-8346 e o período de 1997 a 2019, observa-se que também houve uma forte redução (266.134) nas matrículas dos anos iniciais do ensino fundamental.

Essa tendência de perda constante de matrículas nas redes estadual e municipal é um fato claramente evidenciado pelo quase perfeito paralelismo das duas curvas (sentido decrescente), as quais apresentam inclinações semelhantes no referido período.

O processo de municipalização, no período, foi também expressivo. Em 1997, era de 67,2\%, e 14 anos depois (2011), aumentou para $87,1 \%$. O processo de municipalizando continuou nos anos seguintes, e, em 2019, atingiu o percentual de 99,1\%, ou seja, quase 100\% das matrículas nos iniciais do ensino fundamental no Piauí são ofertadas pelas redes municipais.

No estudo de Sales e Silva (2013), foi constatado que as matrículas da rede municipal cresceram fortemente de 1997 a 1999; ao contrário, a rede estadual apresentou, gradativamente, redução em suas matrículas. Assim sendo, pode-se afirmar que, no referido período, o crescimento das matrículas da rede municipal, antes mesmo da vigência do Fundef, pode ser entendido como uma corrida antecipada dos municípios por matrícula com o fim de aumentar suas receitas. Dito de outro modo, "as redes municipais se anteciparam no incremento de matrículas de modo a se precaverem quanto aos impactos sobre suas receitas" (BASSI e FERMINO 2011, p. 16),

Nesse contexto, pode-se afirmar que, no Piaú, semelhante ao que aconteceu na maioria dos estados brasileiros, houve municipalização nos anos iniciais do ensino fundamental no período de 1997 a 2019.

Finalmente, são analisadas as matrículas dos anos finais do ensino fundamental do Piauí, observando-se a movimentação ocorrida nas matrículas das duas redes consideradas.

Pode ser observada, pela Tabela 3 e pelo Gráfico 3, a movimentação das matrículas dos anos finais do ensino fundamental no Piauí na rede estadual e municipal.

TABELA 3 - Matrículas dos anos finais do ensino fundamental no Piauí das redes estadual e municipal (1997-2019)

\begin{tabular}{c|c|c|c|c|c}
\hline ANO & ESTADUAL & MUNICIPAL & $\begin{array}{c}\text { MATRÍCULA } \\
\text { TOTAL }\end{array}$ & ESTADUAL ( \% ) & MUNICIPAL ( \% ) \\
\hline $\mathbf{1 9 9 7}$ & 80.014 & 32.611 & 112.625 & 71,0 & 29,0 \\
\hline $\mathbf{2 0 1 1}$ & 61.249 & 151.565 & 212.814 & 28,8 & 71,2 \\
\hline $\mathbf{2 0 1 2}$ & 60.413 & 153.344 & 213.757 & 28,3 & 71,7 \\
\hline $\mathbf{2 0 1 3}$ & 53.562 & 155.276 & 208.838 & 25,6 & 74,4 \\
\hline 2014 & 49.537 & 152.214 & 201.751 & 24,6 & 75,4 \\
\hline $\mathbf{2 0 1 5}$ & 45.604 & 147.067 & 192.671 & 23,7 & 76,3 \\
\hline $\mathbf{2 0 1 6}$ & 42.209 & 145.549 & 187.758 & 22,5 & 77,5 \\
\hline $\mathbf{2 0 1 7}$ & 38.377 & 145.333 & 183.710 & 20,9 & 79,1 \\
\hline $\mathbf{2 0 1 8}$ & 35.815 & 145.056 & 180.871 & 19,8 & 80,2 \\
\hline $\mathbf{2 0 1 9}$ & 33.499 & 144.050 & 177.549 & 18,9 & 81,1 \\
\hline
\end{tabular}

Fonte: Elaborado pelos autores a partir de dados do Inep. 
Revista Educação e Políticas em Debate - v. 10, n. 1, p. 243-261, jan./abr. 2021 - ISSN 2238-8346

GRÁFICO 3 - Matrículas dos anos finais do ensino fundamental no Piauí das redes estadual e municipal (1997-2019)

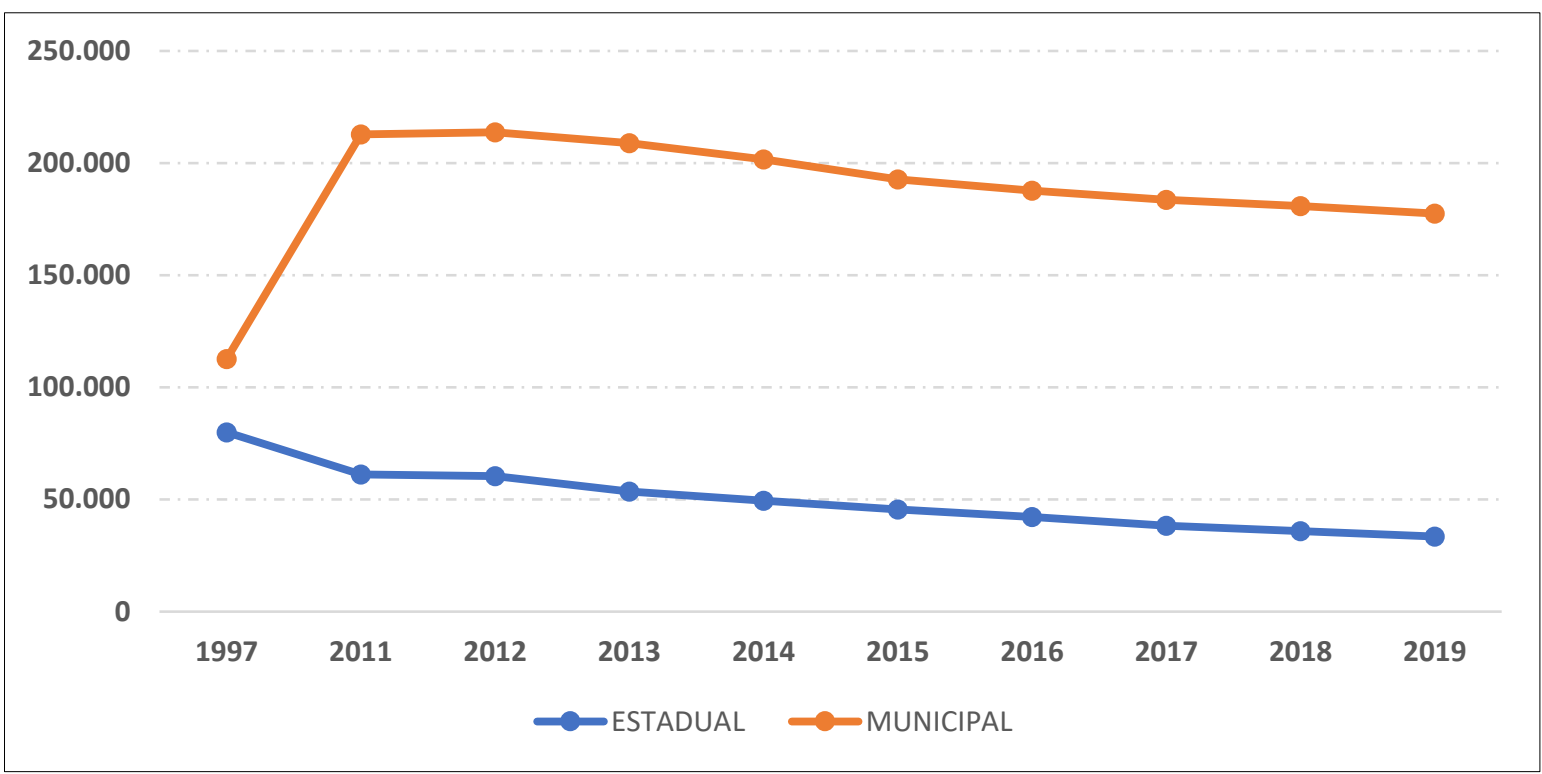

Fonte: Elaborado pelos autores a partir de dados do Inep.

Conforme a Tabela 3 e o Gráfico 3, em 1997, nos anos finais do ensino fundamental, a rede estadual possuía mais matrículas (80.014) que as redes municipais piauienses (32.611). Em 2011, essa situação se inverte, pois as redes municipais piauienses (151.565) superaram em número de matrículas a rede estadual (61.259). Em 2019, as redes municipais perderam 7.515 alunos nos anos finais do ensino fundamental; de forma mais expressiva, a rede estadual perdeu 27.750 alunos.

Em relação à municipalização, o percentual de municipalização dos anos finais do ensino fundamental no Piauí era de 29,0\% em 2011, subiu para 71,2\%, e em 2019 atingiu 81,1\%, contrariando a tendência, apontada por Callegari (2011), de as redes municipais se especializarem nos anos iniciais e as redes estaduais nos anos finais do ensino fundamental. Considerando o expressivo percentual de municipalização dos anos iniciais do ensino fundamental (99,1\%) e o elevado percentual de municipalização de seus anos finais, pode-se afirmar que o atendimento no ensino fundamental, em 2019, no estado do Piauí está bastante municipalizado.

\section{Conclusão}

Este artigo teve como objetivo analisar as matrículas do ensino fundamental no estado do Piauí das redes estadual e municipais no período entre 1997 e 2019. Nesse recorte temporal, levou-se em consideração o primeiro ano de vigência do Fundef (1997) e oito anos de vigência do Fundeb (2011 a 2019), fundos que alteraram a lógica de financiamento da 
Revista Educação e Políticas em Debate - v. 10, n. 1, p. 243-261, jan./abr. 2021 - ISSN 2238-8346 educação nos estados, nos municípios e no Distrito Federal, e, portanto, trouxeram novos elementos para a oferta do ensino fundamental, etapa da educação básica analisada.

A análise aqui realizada tomou como referência os estudos de Callegari (2011), Arelaro (2007), Pinto e Guimarães (2001), Bassi e Fermino (2011). Esses autores reconhecem que o processo de municipalização teve início bem antes da instituição do Fundef, no entanto foi somente a partir dele que a municipalização ganhou um ritmo mais acelerado, não obtido com a legislação anterior. Nesse sentido, Militão (2011) e Souza e Faria (2004) afirmam que outros fatores, relacionados à legislação, também contribuíram para o referido processo de municipalização, tais como a Lei 5.692/71, a CF/88 e a LDB/96.

Ao se analisar a movimentação das matrículas dos anos iniciais do ensino fundamental no Piauí, observou-se que, semelhante ao que ocorreu na maioria dos estados brasileiros, de 1997 a 2019, ocorreu municipalização nessa etapa de ensino.

Tal afirmação é evidenciada na análise da Tabela 2 e do Gráfico 2 , uma vez que o percentual de municipalização que, em 1997, era de 67,2\%, subiu para 87,1\% em 2011. O processo de municipalização continuou nos anos seguintes e, em 2019, atingiu o percentual de 99,1\%, ou seja, quase $100 \%$ das matrículas nos iniciais do ensino fundamental no Piauí são ofertadas pelas redes municipais.

A municipalização transferiu muitos alunos da rede estadual para as redes municipais, o que provocou uma forte redução das matrículas da rede estadual. Paradoxalmente, apesar da forte municipalização dos anos iniciais do ensino fundamental no Piaú́, observou-se redução nas matrículas nas redes municipais, embora esta tenha recebido muitos alunos da rede estadual.

Em relação às matrículas dos anos finais do ensino fundamental, em 1997, a rede estadual possuía mais matrículas que as redes municipais piauienses, 80.014 e 32.611, respectivamente. Em 2011 essa situação se inverte, pois as matrículas das redes municipais piauienses superaram em muito as matrículas da rede estadual - 151.565 nas redes municiais e 61.259 na estadual. Em 2019, as redes municipais perderam 7.515 alunos nos anos finais do ensino fundamental; de forma mais expressiva, a rede estadual perdeu 27.750 alunos. Em síntese, as duas redes perderam matrículas, sendo que as redes municipais, embora tenham recebido bastantes alunos da rede estadual pelo processo de municipalização, mesmo assim não apresentaram aumento no número de matrículas, ao contrário, elas diminuíram.

Em relação à municipalização, o percentual de municipalização dos anos finais do ensino fundamental no Piaú́, em 1997, era de 29,0\%; subiu para 71,2\% em 2011; e em 2019, atingiu $81,1 \%$, contrariando a tendência, apontada por Callegari (2011), de as redes municipais se especializarem nos anos iniciais e as redes estaduais nos anos finais do ensino 
Revista Educação e Políticas em Debate - v. 10, n. 1, p. 243-261, jan./abr. 2021 - ISSN 2238-8346 fundamental. Considerando o expressivo percentual de municipalização dos anos iniciais do ensino fundamental $(99,1 \%)$ e o elevado percentual de municipalização dos anos finais dessa etapa de ensino, pode-se afirmar que o atendimento no ensino fundamental, em 2019, no estado do Piauí, está bastante municipalizado.

A partir dos resultados apresentados, ficou evidenciado que o processo de municipalização das matrículas do ensino fundamental no Piaú teve características peculiares. Tal processo não ocorreu somente nos anos iniciais do ensino fundamental, como era de se esperar, mas veio a configurar-se fortemente nos anos finais dessa etapa de ensino. As razões das peculiaridades da municipalização das matrículas do ensino fundamental no Piauí e os contextos econômicos e políticos, por não terem sido objeto deste artigo, ficarão como objeto de futuras pesquisas.

\section{Referências}

AMARAL, Nelson Cardoso. Financiamento da educação básica e o PNE 2011- 2020.

Revista Retratos da Escola, Brasília, v. 4, n. 6, p. 123-141, jan./jun. 2010.

ARELARO, Lisete Regina Gomes. FUNDEF: uma avaliação preliminar dos dez anos de sua implantação. (GT: Estado e Política Educacional; n. 05, 2007). Disponível em: http://www.anped.org.br/reunioes/30ra/trabalhos/GT05-3866-- Int.pdf. Acesso em: 18 jul. 2020.

AZANHA, José Mário Pires. Uma idéia sobre a municipalização do ensino. Estudos Avançados. vol. 5, n. 12. São Paulo, mai/ago. 1991. Disponível em:

https://www.scielo.br/scielo.php?pid=S0103-40141991000200005\&script=sci_arttext.

Acesso em set. 2020. DOI: https://doi.org/10.1590/s0103-40141991000200005.

BASSI, Marcos Edgar. FERMINO, Phelipe Pires. O Atendimento à Educação Básica em

Santa Catarina: repercussões do FUNDEF e do FUNDEB na matrícula pública. 2011.

Disponível em: http:// nupefe.blogspot.com/2010/09/o-atendimento-educacao-basica-emsanta.html. Acesso em: 20 jul. 2011.

BRASIL. Lei $\mathbf{n}^{\mathbf{o}} \mathbf{5 . 6 9 2}$, de 11/08/1971, Fixa Diretrizes e Bases para o ensino de $1^{\circ} \mathrm{e}$ $2^{\circ}$ graus, e dá outras providências. 1971. Disponível em:

http://www.planalto.gov.br/ccivil_03/Leis/L5692.htm. Acesso em: 20 jul. 2011.

BRASIL. Constituição (1988). Constituição da República Federativa do Brasil. Brasília, DF: Senado Federal, 1988. Disponível em:

http://www.planalto.gov.br/ccivil_03/Constituicao/Constituicao.htm. Acesso em: 20 jul. 2011.

BRASIL. Emenda Constitucional no 14, de 12/09/1996. Modifica os artigos. 34, 208, 211 e 212 da Constituição Federal e dá nova redação ao art. 60 do Ato das Disposições constitucionais Transitórias. 1996a. Disponível em:

http://www.planalto.gov.br/ccivil_03/Constituicao/Emendas/Emc/emc14.htm.

Acesso em: 20 jul. 2011. 
Revista Educação e Políticas em Debate - v. 10, n. 1, p. 243-261, jan./abr. 2021 - ISSN 2238-8346

BRASIL. Lei $\mathbf{n}^{\mathbf{0}}$ 9.394, de 20/12/1996. Estabelece as diretrizes e bases da educação nacional.1996b. Disponível em: http://www.planalto.gov.br/ccivil_03/

Leis/L9394.htm. Acesso em: 20 jul.2011.

BRASIL. Lei n⿳ 9.424, de 24/12/1996. Dispõe sobre o Fundo de Manutenção e Desenvolvimento do Ensino Fundamental e de Valorização do Magistério. 1996c. Disponível em:

http://www.planalto.gov.br/ccivil 03/Leis/L9424.htm. Acesso em: 20 jul. 2011.

CALLEGARI, César. Uma Nova Supervisão para um Novo Mapa Educacional

Paulista. Disponível em: http://www.cesarcallegari.com.br/artigos/Download/ nova\%20sup\%20um\%20novo\%20mapa\%20educ.doc. Acesso em: 20 jul. 2011.

CASTRO, Jorge Abrahão de; DUARTE, Bruno de Carvalho. Descentralização da

Educação pública no Brasil: evolução dos gastos e matrículas. 2007. 25 f. Disponível em: http://www.anped.org.br/sites/default/files/trabalho_encomendado_gt05___int.pdf.

Acesso em: 15 abr. 2020.

CRUZ, Rosana Evangelista; SONOBE Aline Kazuko. A oferta do Ensino Fundamental no contex to do FUNDEB. FINEDUCA - Revista de Financiamento da Educação, v. 10, n. 23, 2020. http://dx.doi.org/10.22491/fineduca-2236-5907-v10-104091. Acesso em 12 out. 2020. DOI: https://doi.org/10.22491/fineduca-2236-5907-v10-103698.

FARENZENA, Nalú. A Política de Fundos e as Responsabilidades Federativas pela Oferta de Educação Básica. FINEDUCA - Revista de Financiamento da Educação, v. 10, n. 21 , 2020. Disponível em: http://seer.ufrgs.br/fineduca. Acesso em out. 2020. DOI:

https://doi.org/10.22491/fineduca-2236-5907-v10-103641.

GUIMARÃES, José Luiz; PINTO, José Marcelino Rezende. A Demanda pela Educação Infantil e os Recursos Disponíveis para seu Financiamento. Em Aberto, Brasília, v. 18, n. 74 , p. 92-105, dez. 2001.

INEP. Instituto Nacional de Estudos e Pesquisas Educacionais Anísio Teixeira. Sinopses Estatísticas da Educação Básica - 199 a 2019. Brasília, 2020. Disponível em:

http://inep.gov.br/sinopses-estatisticas-da-educacao-basica. Acesso em: 12 abr. 2020.

LEMME, Paschoal. O Manifesto dos Pioneiros da Educação Nova e suas Repercussões na Realidade Educacional Brasileira. Revista Brasileira de Estudos Pedagógicos, Brasília, p. 172, v. 86, n. 212, p. 1-233, jan./abr. 2005. DOI: https://doi.org/10.24109/21766681.rbep.86i212.854.

MILITÃO, Silvio César Nunes. Municipalização do Ensino Fundamental em

São Paulo: o FUNDEF como divisor de águas. 2010. Disponível em:

http://forum.ulbratorres.com.br/2010/mesatexto/MESA\%206\%20C.pdf. Acesso em: 20 jul. 2011.

PINTO, José Marcelino Rezende. Federalismo, descentralização e planejamento da educação: desafios aos municípios. Cadernos de Pesquisa v.44 n. 153 p.624-644 jul./set.

2014.Disponível em: http://dx.doi.org/10.1590/198053142946. Acesso em: 20 de abr.2020. DOI: https://doi.org/10.1590/198053142946. 
Revista Educação e Políticas em Debate - v. 10, n. 1, p. 243-261, jan./abr. 2021 - ISSN 2238-8346

PINTO, José Marcelino Rezende. ALVES, Thiago As Múltiplas Realidades Educacionais dos Municípios no Contexto do Fundeb. FINEDUCA - Revista de Financiamento da Educação, v. 10, n. 23, 2020. Disponível em: http://seer.ufrgs.br/fineduca. Acesso em out. 2020. DOI: https://doi.org/10.22491/fineduca-2236-5907-v10-104091.

SOUZA, Donaldo Bello de; FARIA, L. C. Macedo de. Reforma do Estado, Descentralização e Municipalização do Ensino no Brasil: a gestão política dos sistemas públicos de ensino pósLDB 9.394/96. Ensaio: Avaliação e Políticas Públicas em

Educação, Rio de Janeiro, v. 12, n. 45, p. 925-944, out./dez. 2004. Acesso em: 12 abr. 2020. DOI: https://doi.org/10.1590/s0104-40362004000400002.

SALES, Luis Carlos; SALES E SILVA, Magna J. G de A Movimentação das Matrículas no Ensino Fundamental no Estado do Piauí. Educação \& Realidade, Porto Alegre, v. 38, n. 4, p. 1283-1301, out./dez. 2013. Disponível em: http://www.ufrgs.br/edu_realidade. Acesso em set. 2020. DOI: https://doi.org/10.1590/s2175-62362013000400015. 